\title{
Reversal and Prevention of the Respiratory-Depressant Effects of Heroin by the Novel $\mu$-Opioid Receptor Antagonist Methocinnamox in Rhesus Monkeys
}

\author{
Lisa R. Gerak, David R. Maguire, James H. Woods, Stephen M. Husbands, Alex Disney, \\ and Charles P. France
}

Departments of Pharmacology (L.R.G., D.R.M., J.H.W., C.P.F.) and Psychiatry (C.P.F.) and Addiction Research, Treatment \& Training Center of Excellence (L.R.G., D.R.M., J.H.W., C.P.F.), University of Texas Health Science Center at San Antonio, San Antonio, Texas; and Department of Pharmacy and Pharmacology, University of Bath, Bath, United Kingdom (S.M.H., A.D.)

Received August 29, 2018; accepted November 19, 2018

\begin{abstract}
One consequence of the ongoing opioid epidemic is a large number of overdose deaths. Naloxone reverses opioid-induced respiratory depression; however, its short duration of action limits the protection it can provide. Methocinnamox (MCAM) is a novel opioid receptor antagonist with a long duration of action. This study examined the ability of MCAM to prevent and reverse the respiratory-depressant effects (minute volume $\left[\mathrm{V}_{\mathrm{E}}\right]$ ) of heroin in five monkeys. MCAM $(0.32 \mathrm{mg} / \mathrm{kg})$ was given before heroin to determine whether it prevents respiratory depression; heroin dose-effect curves were generated 1, 2, 4, and 8 days later, and these effects were compared with those of naltrexone $(0.032 \mathrm{mg} / \mathrm{kg})$. Heroin dose dependently decreased $\mathrm{V}_{\mathrm{E}}$. MCAM and naltrexone prevented respiratory depression, shifting the heroin dose-effect curve rightward at least 10-fold. MCAM, but
\end{abstract}

not naltrexone, attenuated these effects of heroin for 4 days. MCAM (0.1-0.32 mg/kg) was given 30 minutes after heroin to determine whether it reverses respiratory depression; heroin dose-effect curves were generated 1, 2, 4, 8, and 16 days later, and these effects were compared with those of naloxone $(0.0032-0.1 \mathrm{mg} / \mathrm{kg})$. MCAM and naloxone reversed respiratory depression within 30 minutes, although only MCAM antagonized heroin on subsequent days. Thus, MCAM prevents and reverses respiratory depression, the potentially lethal effect of heroin, longer than opioid receptor antagonists currently in use. Because of its sustained effects, MCAM might provide more effective rescue from and protection against the fatal respiratorydepressant effects of opioids, thereby improving treatment of opioid overdose.

\section{Introduction}

Opioid overdose remains a serious public health problem with the US Centers for Disease Control reporting that more than 100 Americans die every day from opioid overdose (https://wonder.cdc.gov). In response to this growing epidemic, the opioid receptor antagonist naloxone (Narcan) is increasingly available to reverse respiratory depression, the fatal effect of opioids, and remains the only pharmacotherapy for treating opioid overdose (McDonald and Strang, 2016). Naloxone is a reversible antagonist at opioid receptors, and it can attenuate agonist effects, including respiratory depression; however, its therapeutic utility is limited by its short duration of action. For example, the antagonist effects of naloxone can wane before those of the opioid that produced the

This work was supported by the National Institutes of Health (NIH) National Institute on Drug Abuse [Grants R01DA05018 (C.P.F.) and R01DA07315 (S.M.H.)] and by the Welch Foundation [Grant AQ-0039 (C.P. F.)]. All funding sources had no involvement beyond financial support of this study. The content is solely the responsibility of the authors and does not represent the official views of the NIH or the National Institute on Drug Abuse. The authors have no conflict of interest.

https://doi.org/10.1124/jpet.118.253286. overdose, resulting in a re-emergence of respiratory depression after rescue with an acute injection of naloxone (Dahan et al., 2010). In addition, the antagonist effects of naloxone are surmountable, which means that fatal respiratory depression can occur, even in the presence of naloxone, if patients continue to take opioids. Even though naloxone has saved lives, an antagonist that is longer lasting and insurmountable could save many more, if available.

Methocinnamox (MCAM) is an opioid receptor antagonist. The interaction between MCAM and $\mu$-opioid receptors has been termed pseudo-irreversible because binding of $\left[{ }^{3} \mathrm{H}\right] \mathrm{DAMGO}$, a ligand selective for $\mu$-opioid receptors, is markedly decreased in washed membranes obtained from mice 1 hour after MCAM administration (Broadbear et al., 2000); this insurmountable binding suggests an irreversible interaction between MCAM and $\mu$-opioid receptors, which occurs despite the fact that cinnamoylamidomorphinans, the chemical class that includes MCAM, do not alkylate $\mu$-opioid receptors (Zernig et al., 1995; McLaughlin et al., 1999). MCAM attenuates the antinociceptive effects of morphine in rodents, shifting the morphine dose-effect curve to the right up to 100-fold (Peckham et al., 2005) with antagonist effects still evident 2 days after administration 
(Broadbear et al., 2000). Other drugs, including buprenorphine and methoclocinnamox, have been shown to provide long-lasting antagonism of the antinociceptive as well as the respiratorydepressant effects of $\mu$-opioid receptor agonists in monkeys (Walker et al., 1995; Butelman et al., 1996; Kishioka et al., 2000a); however, they have agonist effects at $\mu$-opioid receptors, serving as positive reinforcers, producing antinociceptive effects, and decreasing respiration when given alone (Winger et al., 1992; Walker et al., 1995; Butelman et al., 1996; Briscoe et al., 2000). In contrast, MCAM does not appear to have agonist actions at opioid receptors, and this pharmacological profile of persistent antagonist effects without agonist actions could be exploited to improve treatment of opioid overdose.

In addition to its potential utility for reversing overdose, MCAM could also be useful for treating opioid abuse. Among currently available pharmacotherapies, methadone and buprenorphine are $\mu$-opioid receptor agonists, sharing some effects with and producing similar adverse effects as abused opioids, including respiratory depression, that can be exacerbated when opioids are combined with other drugs such as ethanol or benzodiazepines (e.g., Hall et al., 2008; Jones et al., 2012, 2014; Jones and McAninch, 2015). Naltrexone, the only opioid receptor antagonist used to treat opioid abuse, avoids those adverse effects and drug interactions; however, the pharmacological profile of naltrexone is similar to that of naloxone in terms of its short duration of action as well as the surmountability of antagonist effects. Although novel formulations are available to reduce some of the limitations of these treatments [e.g., buprenorphine and naloxone (Suboxone) to decrease abuse liability, slow-release naltrexone (Vivitrol) to extend duration of action], the effects of currently available antagonists are still surmountable, suggesting that the insurmountability of MCAM could provide an important advantage.

This study examined the ability of MCAM to prevent and reverse the respiratory-depressant effects of heroin, which decreases respiration in monkeys, as evidenced by dose-dependent decreases in minute volume ( $\mathrm{V}_{\mathrm{E}}$; e.g., Vivian et al., 1998). Opioid receptor antagonists can prevent and reverse the respiratorydepressant effects of heroin and other $\mu$-opioid receptor agonists (e.g., Gerak et al., 1998; Vivian et al., 1998). In the current study, MCAM was given before heroin to determine whether it prevents respiratory depression, and its effects were compared with those of naltrexone, the only opioid receptor antagonist currently used to treat opioid abuse. In another experiment, MCAM was given after respiration was decreased with heroin to determine whether it reverses respiratory depression, and its effects were compared with those of naloxone, the only drug currently used to reverse opioid overdose. The duration of action of each antagonist was assessed by generating heroin dose-effect curves at various times (up to 16 days) after antagonist administration.

\section{Materials and Methods}

Subjects. Five adult rhesus monkeys (four female, identified here as ME, OL, SC, and CE; one male, GI) participated in this study. They were housed individually in a temperature- and humidity-controlled room that was illuminated from 0600 to 2000 hours. Water was available continuously in the home cage. Body weights $(6.7-10.5 \mathrm{~kg})$ were maintained with daily food rations of either Teklad 20\% Protein Monkey Diet (monkeys ME, OL, CE, and GI) or Teklad High Fiber Monkey Diet (monkey SC; Harlan Teklad, Madison, WI); fresh fruit and peanuts were also provided daily. These monkeys received drugs, including opioids, in previous behavioral experiments (e.g., Weed et al., 2018). Animals used in these studies were maintained in accordance with the Institutional Animal Care and Use Committee, The University of Texas Health Science Center at San Antonio, and the 2011 Guide for the Care and Use of Laboratory Animals (Institute of Laboratory Animal Resources on Life Sciences, National Research Council, National Academy of Sciences, USA).

Apparatus. Experimental sessions were conducted in soundattenuating cubicles that contained house lights and an exhaust fan (model ENV-600A; Med Associates Inc., Fairfax, VT); monkeys could be monitored continuously during experiments by cameras in the cubicles. Monkeys were seated in chairs (model R001; Primate Products, Miami, FL). A customized Lexan mounting platform and a latex neck dam were placed over the head of the monkey followed by a helmet (PlasLaboratories, Lansing, MI), which created a closed chamber. Air was drawn into the helmet by a large animal bias flow supply (Data Sciences International, St. Paul, MN); a constant flow rate of $10 \mathrm{l} / \mathrm{min}$ was monitored using an airflow meter (model 4140F; TSI Inc., Shoreview, MN). With each inspiration of air, a pneumotachometer measured the pressure changes inside the helmet; that analog signal was transformed to digital using a carrier signal conditioner card connected to an acquisition module (Model ACQ-770; Data Sciences International). Those digital signals were then converted to respiratory rate $(f)$ and tidal volume $\left(V_{\mathrm{T}}\right)$ using Ponemah software (version 4.01; Data Sciences International), and minute volume $\left(\mathrm{V}_{\mathrm{E}}\right)$ was calculated by multiplying $f$ and $\mathrm{V}_{\mathrm{T}}$.

General Procedure. For all sessions, $\mathrm{V}_{\mathrm{E}}, \mathrm{V}_{\mathrm{T}}$, and $f$ were measured continuously and collected every minute. No injections were given during the control period comprising the first 30 (monkeys ME, $\mathrm{OL}, \mathrm{CE}$, and GI) or 45 minutes (monkey SC) of the session; monkey SC needed additional time at the beginning of each experiment for breathing to stabilize (see criteria below). Thereafter, the session was divided into 15-minute cycles, with an injection (or sham injection) administered during the first minute of each cycle. Although respiratory parameters were collected continuously, values of $\mathrm{V}_{\mathrm{E}}$ obtained during the last 5 minutes of each interval were averaged to calculate $\mathrm{V}_{\mathrm{E}}$ for that interval (i.e., for the control period as well as for each cycle). Before drugs were administered and periodically thereafter, baseline sessions were conducted during which saline or sham injections were given during each cycle. Drug testing began when two criteria were satisfied for three consecutive sessions, as follows: 1) Within a session, $V_{E}$ for each cycle was at least $80 \%$ of $V_{E}$ obtained during the control period, and 2) across three sessions, the $V_{E}$ obtained during the control periods for each session did not vary by more than $20 \%$ from the mean of those three sessions.

Prevention of Respiratory Depression. Heroin dose-effect curves were generated in monkeys OL, ME, GI, and CE using a cumulative-dosing procedure, whereby the cumulative dose increased by $0.25 \mathrm{log}$ units per cycle. Dosing stopped at the smallest dose that decreased $V_{E}$ to $<70 \%$ of the mean of the last 5 minutes of the control period. For some tests, saline was administered immediately after the control period (i.e., beginning of the first cycle) with the first dose of heroin administered during the second cycle. To examine the ability of MCAM to prevent the respiratory-depressant effects of heroin, a single dose of MCAM $(0.32 \mathrm{mg} / \mathrm{kg})$ was administered in the home cage with heroin dose-effect curves determined 1, 2, 4, and 8 days after MCAM administration; each of these sessions began at the same time of day. On a separate occasion, a single dose of naltrexone $(0.032 \mathrm{mg} / \mathrm{kg})$ was given before redetermination of heroin dose-effect curves; instead of saline, naltrexone was administered during the first cycle with the first dose of heroin administered during the second cycle. A heroin dose-effect curve was also determined 24 hours later. Because of its long duration of action, a minimum of 17 days separated injections of MCAM.

Reversal of Respiratory Depression. To assess the ability of MCAM and naloxone to reverse the respiratory-depressant effects of heroin, an acute dose of heroin that decreased $\mathrm{V}_{\mathrm{E}}$ to $<70 \%$ of control was administered immediately after the control period in monkeys $\mathrm{OL}, \mathrm{ME}, \mathrm{GI}$, and SC; monkey SC replaced monkey $\mathrm{CE}$ because the 
stability criteria described above were no longer reliably satisfied by monkey CE. Because the potency of heroin varied across monkeys, different doses of heroin were used among monkeys for the reversal studies; however, an individual monkey received the same dose of heroin for all studies. Time course for the respiratory-depressant effects of heroin was determined by administering the smallest dose of heroin that decreased VE to $<70 \%$ of control followed by only saline or sham injections every 15 minutes for the remainder of the 2-hour session. A heroin dose-effect curve was generated the next day, as described above for the prevention experiment. Reversal tests with antagonists were conducted on separate occasions with injections of MCAM $(0.1-0.32 \mathrm{mg} / \mathrm{kg})$ or naloxone $(0.0032-0.1 \mathrm{mg} / \mathrm{kg})$ given 30 minutes after heroin. Thereafter, heroin dose-effect curves were redetermined on different days until they were no longer shifted to the right of the curve obtained in the absence of antagonist. For MCAM, heroin dose-effect curves were determined 1, 2, 4, 8, and 16 days and for naloxone 1 day after a reversal test.

Drugs. Heroin $\mathrm{HCl}$, naltrexone $\mathrm{HCl}$, and naloxone $\mathrm{HCl}$ (Drug Supply Program, National Institute on Drug Abuse, Rockville, MD) were dissolved in sterile water. MCAM was synthesized as described previously (Broadbear et al., 2000) and dissolved in a vehicle of $10 \% \mathrm{w} / \mathrm{v}$ $\beta$-cyclodextrin in saline. Drugs were administered subcutaneously.

Data Analyses. Data were collected continuously and transformed to respiration rate (inspirations/min, $f$ ) and tidal volume (ml/inspiration, $\mathrm{V}_{\mathrm{T}}$ ) ; minute volume $\left(\mathrm{ml} / \mathrm{min}, \mathrm{V}_{\mathrm{E}}\right)$ was determined by multiplying $f$ and $\mathrm{V}_{\mathrm{T}}$. The control $\mathrm{V}_{\mathrm{E}}$ for each session was obtained by averaging $\mathrm{V}_{\mathrm{E}}$ obtained during each of the last 5 minutes of the control period. Thereafter, data were averaged across the last 5 minutes of each cycle, expressed as a percentage of control, and plotted as a function of heroin dose or time. Because of the difference in potency of heroin across monkeys, doses were normalized across monkeys such that, in the absence of antagonist, a dose $\mathrm{X}$ was the smallest dose that decreased $\mathrm{V}_{\mathrm{E}}$ to $<70 \%$ of control; the value for $\mathrm{X}$ was determined at the beginning of the studies. For each monkey, dosing of heroin stopped once $\mathrm{V}_{\mathrm{E}}$ was decreased to $<70 \%$ of control and each data point plotted in the figures represents four monkeys; in the event that dosing stopped in a monkey before the group mean was decreased to $<70 \%$ of control, then $\mathrm{V}_{\mathrm{E}}$ was conservatively estimated for all subsequent data points as the value obtained with the largest dose studied in that individual.

The ability of antagonists to reverse heroin-induced respiratory depression was determined by first giving heroin to decrease $\mathrm{V}_{\mathrm{E}}$ to $<70 \%$ of control followed 30 minutes later with an injection of antagonist. The results obtained with each antagonist were analyzed separately using two-way repeated measures analysis of variance (ANOVA) with antagonist dose as one factor and time since antagonist administration as the second factor. When significant differences were found, post-hoc analyses were conducted using Dunnett's multiple comparisons tests. Data analyses were performed using GraphPad Prism (version 6.07; GraphPad, La Jolla, CA). Effects were considered significant when $P<0.05$.

Changes in dose-effect curves were analyzed by first calculating the doses of heroin needed to decrease $\mathrm{V}_{\mathrm{E}}$ to $75 \%\left(\mathrm{ED}_{75}\right)$. For each monkey, effective doses were obtained by interpolation using one data point directly above and one data point directly below $75 \%$. The values were then averaged across monkeys to obtain a mean $\mathrm{ED}_{75}$ value for each dose-effect curve, and time-effect curves were generated for each effect level by plotting the mean values as a function of time since antagonist administration. Results obtained for each antagonist were analyzed separately using a oneway ANOVA with time since antagonist administration as the factor (MCAM and naltrexone) or using a paired $t$ test (naloxone). Data analyses were performed using NCSS (version 10; NCSS, LLC, Kaysville, UT) and GraphPad Prism (version 6.07; GraphPad, La Jolla, CA). Effects were considered significant when $P<0.05$.

\section{Results}

The control mean ( \pm 1 S.E.M.) $\mathrm{V}_{\mathrm{E}}$ was $1586 \pm 101,1392 \pm$ $98,1895 \pm 51,1367 \pm 81$, and $1751.5 \pm 141 \mathrm{ml} / \mathrm{min}$ for subjects OL, ME, SC, CE, and GI, respectively (points above C, left panel, Fig. 1). Heroin dose dependently decreased $V_{E}$ in all monkeys (left panel, Fig. 1), although its potency to decrease respiration to $<70 \%$ of control varied markedly across monkeys. The potency difference is particularly evident when $V_{E}$ is expressed as a percentage of control (right panel, Fig. 1), with heroin being much more potent in monkey OL (circles, Fig. 1) compared with the other four monkeys.

Prevention of Respiratory Depression. On separate occasions, MCAM or naltrexone was administered before determination of a heroin dose-effect curve. When $0.32 \mathrm{mg} / \mathrm{kg}$ MCAM was given 1 day earlier, the heroin dose-effect curve was shifted more than 10 -fold to the right (compare upright triangles and filled circles, upper panel, Fig. 2). MCAM continued to attenuate the effects of heroin for up to 4 days (diamonds, upper panel, Fig. 2) with the heroin dose-effect curve returning to control 8 days after MCAM administration (inverted triangles, Fig. 2). A dose of $0.032 \mathrm{mg} / \mathrm{kg}$ naltrexone also antagonized the respiratory-depressant effects of heroin, shifting the dose-effect curve 10 -fold rightward on the day naltrexone was administered; the heroin dose-effect curve determined 1 day after naltrexone administration was similar to the heroin dose-effect curve determined in the absence of naltrexone (compare triangles and filled circles, bottom panel, Fig. 2).

Reversal of Respiratory Depression. Heroin decreased $\mathrm{V}_{\mathrm{E}}$ to $<70 \%$ of control within 30 minutes (filled circles above 0 , both panels, Fig. 3) with respiratory depression remaining suppressed for the next 60 minutes. MCAM $(0.1$ and $0.32 \mathrm{mg} / \mathrm{kg})$ reversed the respiratory-depressant effects of heroin. There was a significant interaction between dose of MCAM and time since administration of MCAM $(\mathrm{F}[8,24]=2.81 ; P=0.02)$ as well between as significant main effects of dose $(\mathrm{F}[2,6]=6.54$; $P=0.03)$ and time-since-administration $(\mathrm{F}[4,12]=13.14$; $P=0.0002) . \mathrm{V}_{\mathrm{E}}$ was significantly increased 30 minutes after $0.32 \mathrm{mg} / \mathrm{kg} \mathrm{MCAM}$ and 45 minutes after $0.1 \mathrm{mg} / \mathrm{kg} \mathrm{MCAM}$, compared with $\mathrm{V}_{\mathrm{E}}$ obtained after administration of heroin alone, and remained significantly increased for the remainder of the session (diamonds and open circles, left panel, Fig. 3). Naloxone also reversed the respiratory-depressant effects of heroin with a significant interaction between dose of naloxone and time since administration of naloxone $(\mathrm{F}[16,48]=2.50$; $P=0.007)$ as well as significant main effects of dose (F $[4,12]$ $5.71 ; P=0.008)$ and time since administration $(\mathrm{F}[4,12]=5.03$; $P=0.013)$. The smallest dose of naloxone $(0.0032 \mathrm{mg} / \mathrm{kg}) \mathrm{did}$ not change $V_{E}$, compared with $V_{E}$ obtained after administration of heroin alone; the three larger doses of naloxone significantly increased $\mathrm{V}_{\mathrm{E}} 15$ minutes after administration, although the increase was no longer evident 30 minutes after administration of 0.01 and $0.032 \mathrm{mg} / \mathrm{kg}$ and 45 minutes after administration of $0.1 \mathrm{mg} / \mathrm{kg}$ (right panel, Fig. 3).

Heroin dose-effect curves were determined on days after reversal tests. The respiratory-depressant effects of heroin were antagonized the day after each dose of MCAM, with greater antagonism observed after $0.32 \mathrm{mg} / \mathrm{kg}$ compared with $0.1 \mathrm{mg} / \mathrm{kg}$ (left panels, Fig. 4). The heroin dose-effect curve returned to control in a dose- and time-dependent manner after administration of MCAM, with the dose-effect curves being similar to control 4 days after administration of $0.1 \mathrm{mg} / \mathrm{kg}$ MCAM and 16 days after administration of $0.32 \mathrm{mg} / \mathrm{kg}$ MCAM (upper and lower left panels, respectively; Fig. 4). In contrast, although the largest dose of naloxone $(0.1 \mathrm{mg} / \mathrm{kg})$ completely 


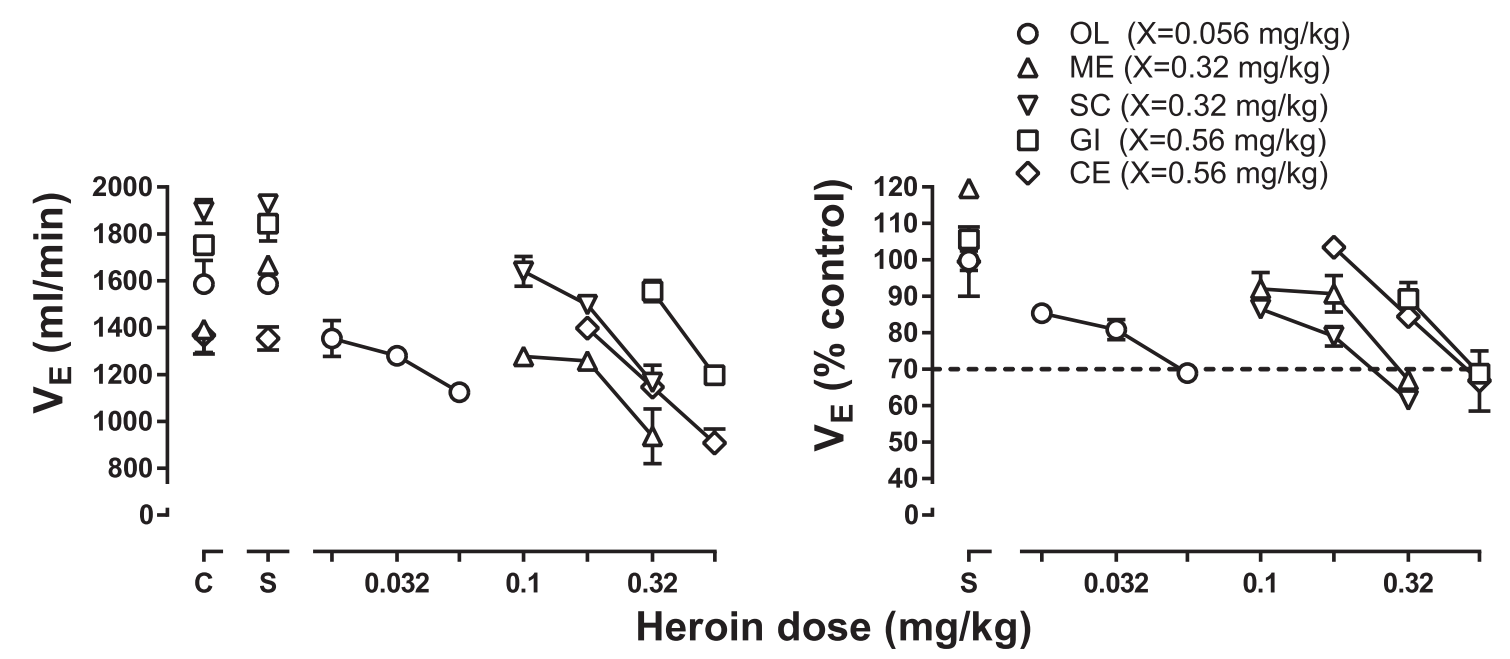

Fig. 1. Potency for heroin to decrease respiration across monkeys. The average of two heroin dose-effect curves determined in the absence of antagonist are shown with each symbol representing data from a different monkey. Because the potency of heroin varied across monkeys, the smallest dose of heroin that decreased $\mathrm{V}_{\mathrm{E}}$ to $<70 \%$ of control was designated dose $\mathrm{X}$ and used to normalize dose-effect curves to compare results of antagonism studies (Figs. 2 and 4). Abscissae: heroin dose in milligrams per kilogram of body weight. Ordinates: minute volume $\left(\mathrm{V}_{\mathrm{E}}\right)$ in milliliters per minute (left) or expressed as a percentage of control, which was obtained from the last 5 minutes of the control period for that session (right).

reversed the effects of heroin on the day that it was administered (diamonds, right panel, Fig. 3), that dose did not alter the heroin dose-effect curve 1 day later (right panel, Fig. 4).

For each heroin dose-effect curve, doses needed to decrease respiration to $75 \%$ of control $\left(\mathrm{ED}_{75}\right)$ were calculated and plotted as a function of time since antagonist administration. MCAM
$(0.1 \mathrm{mg} / \mathrm{kg}: \mathrm{F}[5,23]=6.50 ; P=0.002 ; 0.32 \mathrm{mg} / \mathrm{kg}: \mathrm{F}[5,23]=$ $6.36 ; P=0.002)$ and naltrexone $(\mathrm{F}[2,11]=11.73 ; P=0.008)$ significantly increased the $\mathrm{ED}_{75}$ value of heroin. Although the antagonist effects of naltrexone and naloxone $(0.1 \mathrm{mg} / \mathrm{kg}$ : $\mathrm{t}=$ $0.072 ; P=0.95$ ) were not statistically significant within 1 day of administration, those of MCAM were significantly changed

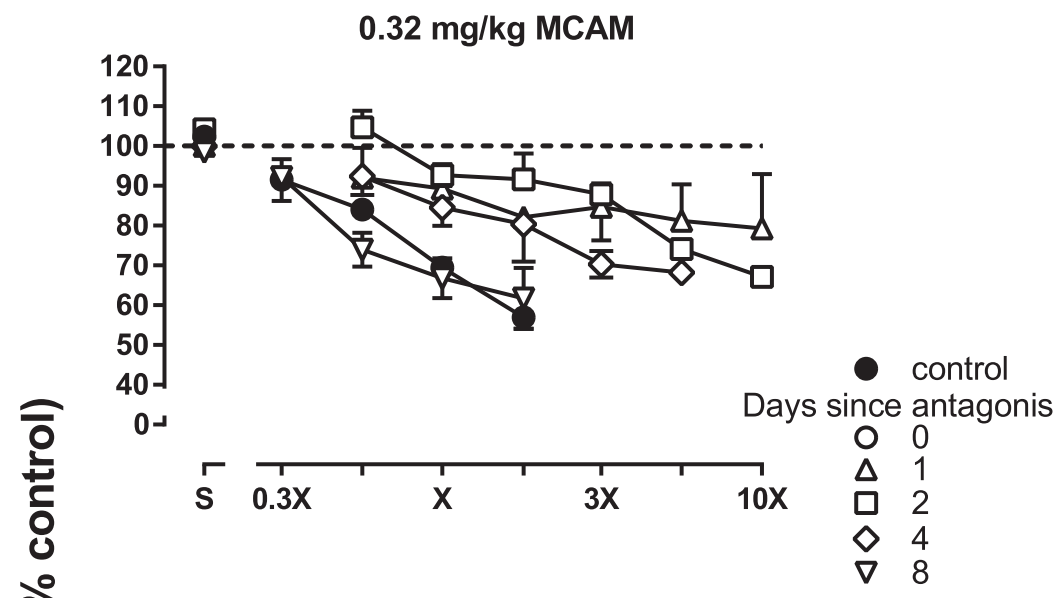

$0.032 \mathrm{mg} / \mathrm{kg}$ Naltrexone

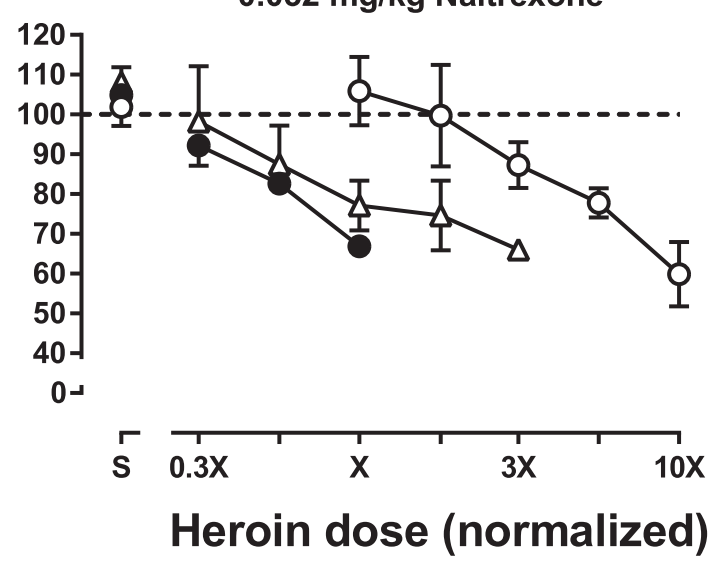

Fig. 2. Prevention of the respiratory-depressant effects of heroin in four monkeys. Heroin dose-effect curves were determined at various times after the administration of MCAM (upper) or naltrexone (lower). Data from OL, ME, $\mathrm{CE}$, and GI are shown in the upper panel, whereas data from OL, ME, SC, and GI are shown in the bottom panel. Heroin doses were normalized across animals such that dose $\mathrm{X}$ is the smallest dose of heroin that decreased $\mathrm{V}_{\mathrm{E}}$ to $<70 \%$ of control (see Fig. 1 for individual doses). Abscissae: normalized heroin dose. Ordinates: minute volume $\left(\mathrm{V}_{\mathrm{E}}\right)$ expressed as a percentage of control. 

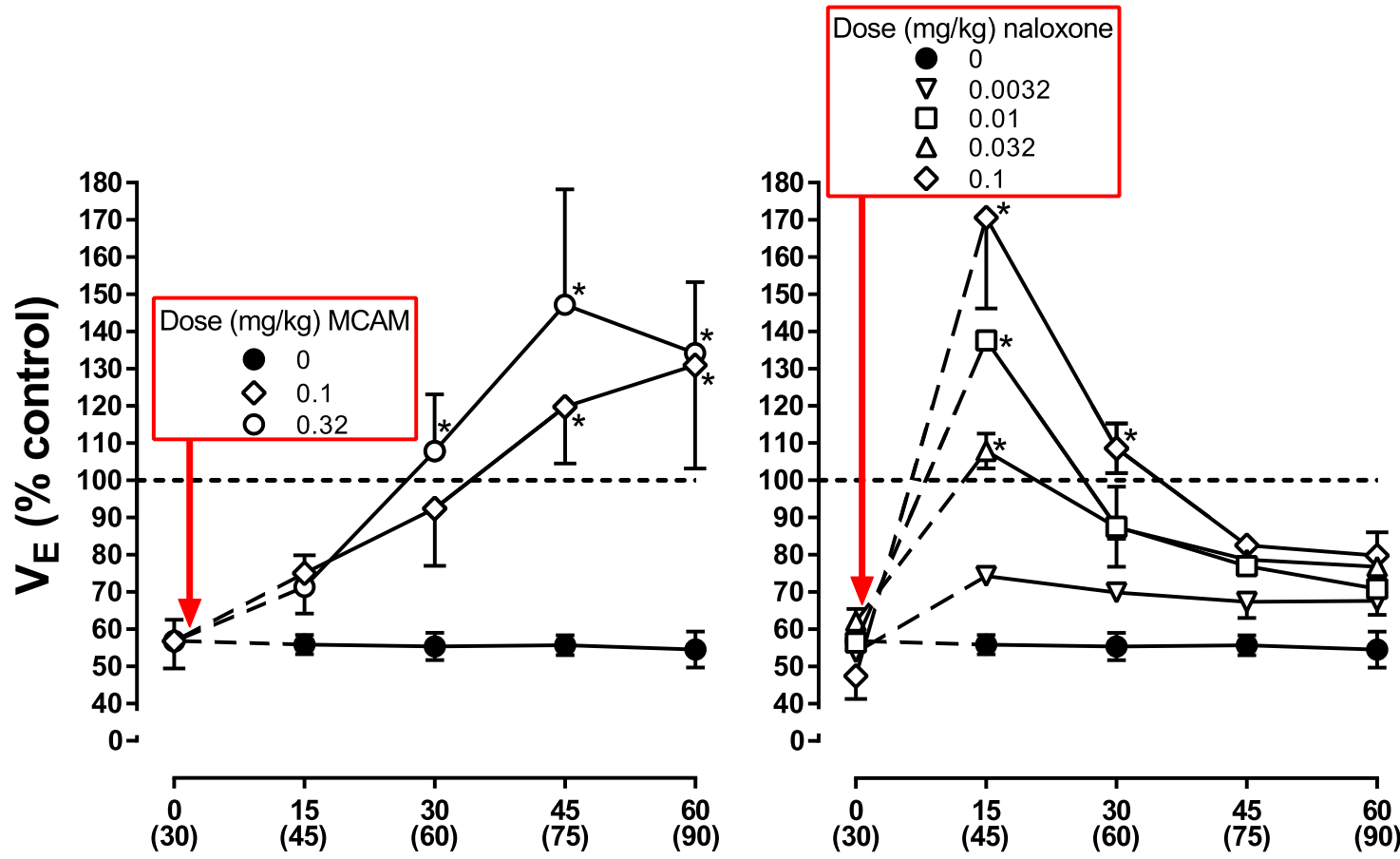

\section{Time [min] since antagonist (Time [min] since heroin)}

Fig. 3. Reversal of the respiratory-depressant effects of heroin in four monkeys. A dose of heroin that decreased $\mathrm{V}_{\mathrm{E}}$ to $<70 \%$ of control when given as a bolus injection was administered with a second injection of either saline, MCAM, or naloxone given 30 minutes later. The dose of heroin needed to produce this effect varied across monkeys (OL: $0.1 \mathrm{mg} / \mathrm{kg}$, ME: $0.32 \mathrm{mg} / \mathrm{kg}$, SC: $0.56 \mathrm{mg} / \mathrm{kg}$, and GI: $1 \mathrm{mg} / \mathrm{kg}$ ). Asterisks indicate that data points obtained following administration of an antagonist are significantly greater than those obtained with heroin alone. Abscissae: time since administration of the second injection with time since heroin administration shown in parentheses. Ordinates: minute volume $\left(\mathrm{V}_{\mathrm{E}}\right)$ expressed as a percentage of control.

when MCAM was given before (prevention, open triangles, upper panel, Fig. 5) or after heroin administration (reversal, open triangles, lower panel, Fig. 5); the $\mathrm{ED}_{75}$ remained significantly increased 4 days after MCAM prevented the effects of heroin and not 4 days after the MCAM was given to reverse the effects of heroin.

\section{Discussion}

One devastating consequence of the current opioid epidemic is the overwhelming number of fatal overdoses, despite the availability of an effective antidote (McDonald and Strang, 2016). Naloxone, the only antagonist used to treat opioid overdose, and naltrexone, the only antagonist used to treat opioid abuse, are both competitive, reversible antagonists at $\mu$-opioid receptors; however, their therapeutic utility (for overdose and abuse, respectively) is limited by their pharmacological properties. For example, because of a short duration of action, the antagonist effects of naloxone can wane before the respiratory-depressant effects of some opioid receptor agonists, potentially resulting in a re-emergence of respiratory depression after rescue (e.g., Dahan et al., 2010; Gatewood et al., 2016; Tomassoni et al., 2017). In addition, the effects of these antagonists are surmountable, so that fatal respiratory depression can occur, even in the presence of an antagonist, if patients continue to take opioids. MCAM is an opioid receptor antagonist that binds pseudo-irreversibly to $\mu$-opioid receptors (Broadbear et al., 2000); consequently, it should provide sustained and insurmountable protection against respiratory depression and overdose. The present study determined the effectiveness and duration of action of MCAM and compared its ability to prevent respiratory depression to that of naltrexone and its ability to reverse respiratory depression to that of naloxone.

MCAM attenuated completely the respiratory-depressant effects of heroin. When given before heroin, $0.32 \mathrm{mg} / \mathrm{kg}$ MCAM and $0.032 \mathrm{mg} / \mathrm{kg}$ naltrexone antagonized heroin in a similar manner, shifting the heroin dose-effect curve rightward at least 10-fold. Larger doses of each antagonist would be expected to shift the heroin dose-response curve further to the right or upward. Because the presence of other drugs acting at $\mu$-opioid receptors might reduce binding of MCAM, heroin was not administered on the same day as MCAM during prevention studies, and MCAM antagonism of the respiratory-depressant effects of heroin was determined the day after administration of MCAM. Under those conditions, the magnitude of shift of the heroin dose-effect curve was comparable to that produced by $0.032 \mathrm{mg} / \mathrm{kg}$ of naltrexone given 15 minutes before heroin. One striking difference between MCAM and naltrexone was duration of action. MCAM attenuated the respiratory-depressant effects of heroin for at least 4 days, whereas the antagonist effects of naltrexone were gone in 1 day. The persistent effects of MCAM, which are probably attributable to its pseudo-irreversible binding to $\mu$-opioid receptors, could protect overdose patients from respiratory depression caused by re-emergence of effects of an agonist that has a duration of action longer than naloxone or in the event that the patient uses opioids after rescue from overdose. 


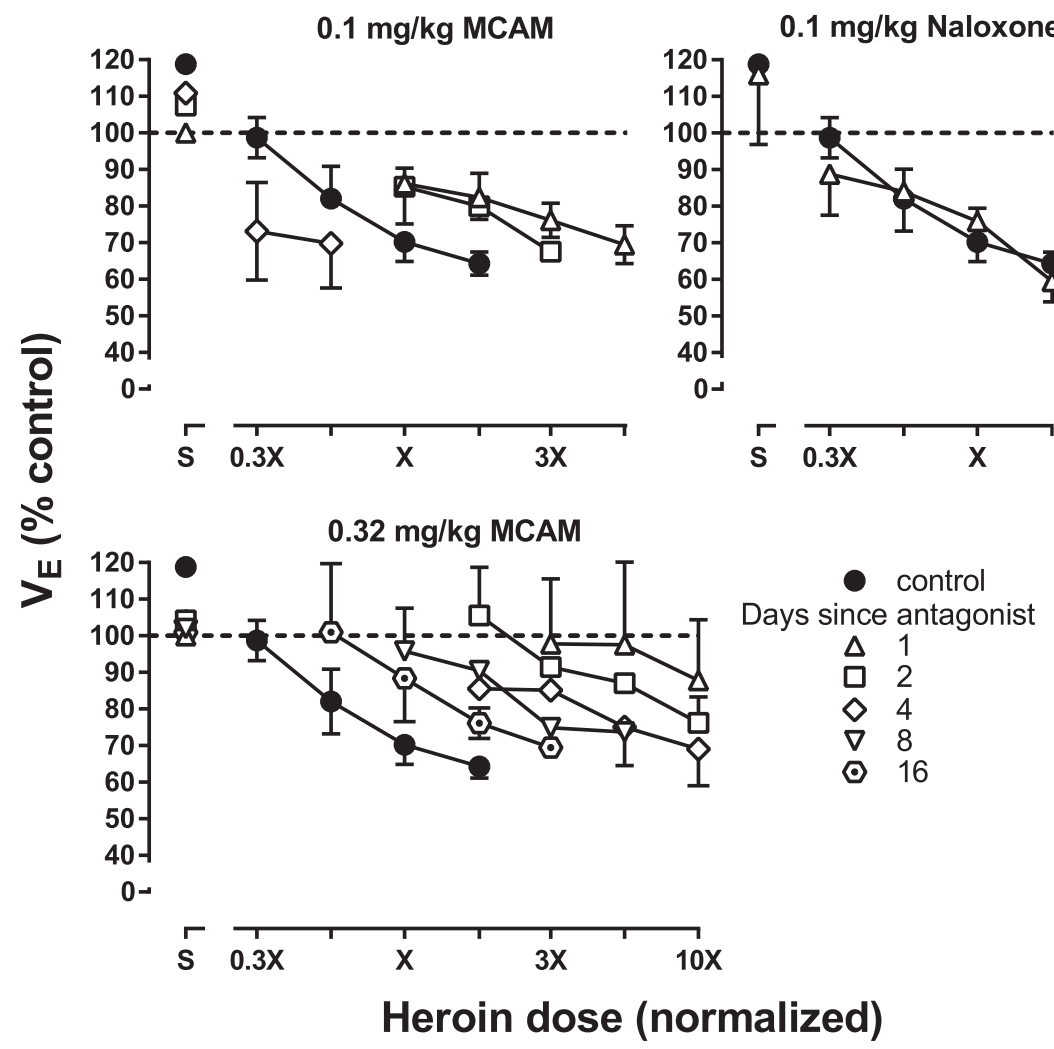

Fig. 4. Heroin dose-effect curves determined on various days after the MCAM or naloxone reversal tests shown in Fig. 3. Only the largest dose of naloxone is shown 1 day after the reversal test. Abscissae: normalized heroin dose. Ordinates: minute volume $\left(\mathrm{V}_{\mathrm{E}}\right)$ expressed as a percentage of control.

Like naloxone, MCAM reversed the respiratory-depressant effects of heroin, although these drugs differed slightly in the time course of these antagonist effects. Naloxone restored $V_{E}$ to control values within 15 minutes. MCAM partially reversed heroin-induced respiratory depression within 15 minutes, although $\mathrm{V}_{\mathrm{E}}$ was not restored fully to control values until 30 minutes after MCAM administration. The partial reversal obtained 15 minutes after MCAM administration might be sufficient to protect individuals from the lethal effects of opioids, even though breathing had not returned to control; however, the much longer duration of action of MCAM, compared with naloxone, could provide a distinct clinical advantage. $\mathrm{V}_{\mathrm{E}}$ remained above $100 \%$ of control levels for at least 60 minutes after MCAM administration, whereas $\mathrm{V}_{\mathrm{E}}$ returned to below control values within 45 minutes after administration of the largest dose of naloxone. This observation is consistent with a major limitation of naloxone when it is used clinically to reverse the effects of an opioid that lasts longer than naloxone (e.g., Dahan et al., 2010; Gatewood et al., 2016; Tomassoni et al., 2017). Moreover, 1 day after a reversal test, when the effects of the acute dose of heroin were no longer evident, the heroin dose-effect curve was shifted to the right in monkeys that received MCAM the preceding day (i.e., during the reversal test) but not in monkeys that received $0.032 \mathrm{mg} / \mathrm{kg}$ naloxone or saline the preceding day. Thus, MCAM protects against the respiratory-depressant effects of heroin on the day that MCAM is administered as well as on subsequent days when additional doses of heroin are given. Collectively, these results demonstrate that a single injection of MCAM reverses heroin-induced respiratory depression and protects against subsequent drug-induced respiratory depression for a much longer period than naloxone, which is the only drug available currently for treating overdose.
Differences across monkeys in control $\mathrm{V}_{\mathrm{E}}$ and in the potency of heroin (Fig. 1) have been shown previously, with monkey OL being the most sensitive and monkey GI being the least sensitive to the effects of opioids (Weed et al., 2018). Despite these well documented differences, the effects of heroin and the antagonists were remarkably consistent throughout these studies, with little variation in heroin dose-effect curves determined in the absence of antagonist (Fig. 1) and those determined after the effects of the antagonist were no longer evident (e.g., 1 day after either naltrexone or naloxone). Moreover, in monkeys, $0.032 \mathrm{mg} / \mathrm{kg}$ naltrexone reliably shifts the opioid agonist dose-effect curve to the right 10-fold (e.g., current study; France et al., 1990; Gerak and France, 2007). The effects of a single dose of heroin are also quite consistent with decreased $\mathrm{V}_{\mathrm{E}}$ not changing significantly within session (solid circles, Fig. 3) or across different determinations (points above 0 , Fig. 3 ). The time course of recovery of the heroin doseeffect curve after administration of $0.32 \mathrm{mg} / \mathrm{kg}$ MCAM was determined twice, separated by at least 2 months. During the prevention experiment, the heroin dose-effect curve returned to control within 8 days of MCAM administration, whereas during the reversal study, the heroin dose-effect curve did not return fully to control values within 8 days. Although this study was not designed to determine the effects of repeated administration of MCAM, these results suggest that such studies are warranted.

During the reversal studies, respiration $\left(\mathrm{V}_{\mathrm{E}}\right)$ increased to above control values (i.e., exceeding $140 \%$ of control) after the administration of naloxone or MCAM. The maximum increase in $\mathrm{V}_{\mathrm{E}}$ occurred 15 minutes after administration of naloxone and 45 minutes after administration of MCAM, consistent with the slower onset of action for MCAM in reversing respiratory depression compared with naloxone. This overshoot 


\section{Prevention}
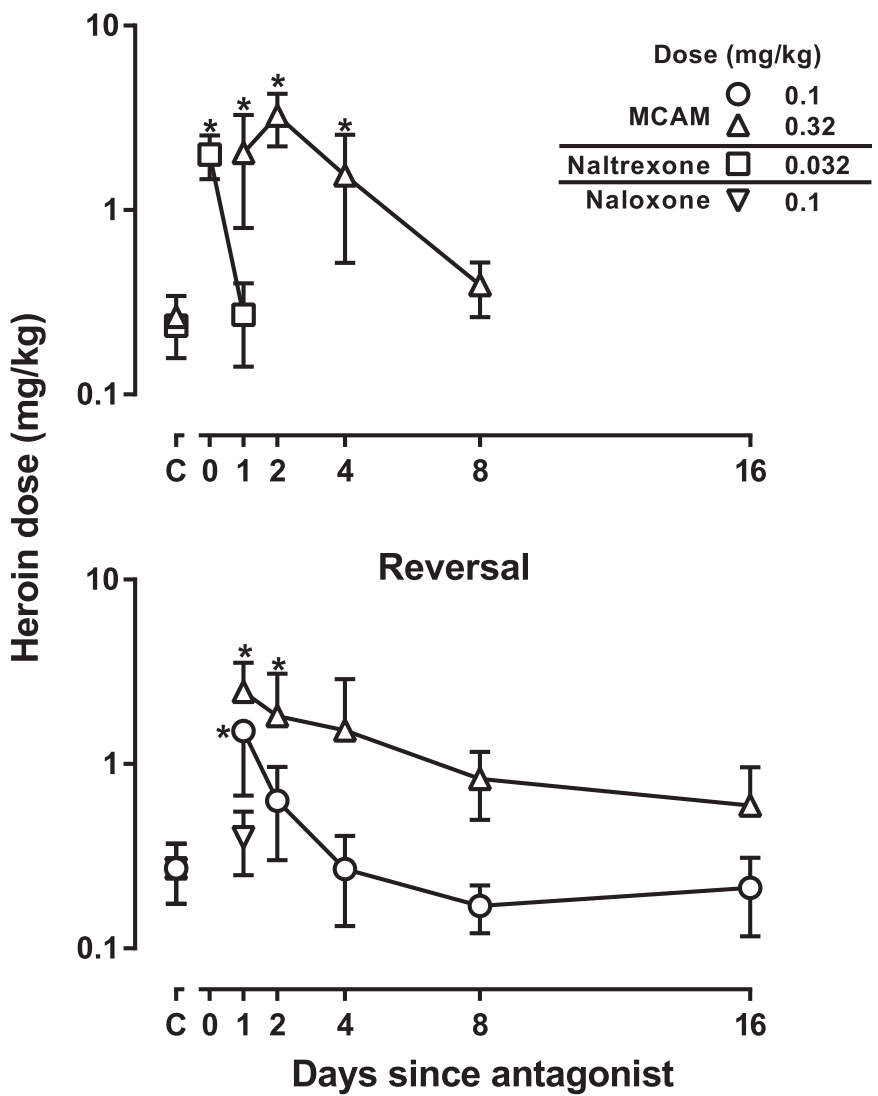

Fig. 5. Doses of heroin that decrease respiration to $75 \%$ at various times after administration of an antagonist. The upper panel, which shows results from the prevention experiments, summarizes dose-effect curves from Fig. 2, and the lower panel, which shows results from the reversal experiments, summarizes data from Fig. 4. Points above $\mathrm{C}$ indicate the $\mathrm{ED}_{75}$ value obtained from heroin dose-effect curves in the absence of antagonist. Asterisks indicate that $\mathrm{ED}_{75}$ values for heroin obtained after administration of an antagonist are significantly different from those obtained with heroin alone. Abscissae: days since antagonist administration. Ordinates: dose (milligrams per kilogram) of heroin needed to decrease $\mathrm{V}_{\mathrm{E}}$ to $75 \%$ of control.

in respiration is probably related to withdrawal signs that emerge in patients who receive naloxone as an antidote for opioid overdose (Avetian et al., 2018). That this effect occurred in monkeys that were not physically dependent on an opioid is consistent with a well-characterized phenomenon known as acute opioid dependence, whereby many characteristic opioid withdrawal signs can be produced by administering a single dose of opioid antagonist in a subject treated with a single dose of opioid agonist (e.g., Kishioka et al., 2000b; Walker and Sterious, 2005). Thus, like naloxone, MCAM would be expected to precipitate withdrawal in an opioid-intoxicated individual, even if that individual is not physically dependent on opioids. Patients taking a dose of an opioid large enough to warrant rescue with an antagonist would probably experience withdrawal symptoms regardless of whether they receive MCAM or naloxone. Moreover, because of the long duration of action of MCAM, precipitated withdrawal could be prolonged, compared with that of naloxone. However, there is emerging evidence that MCAM could have a distinct advantage over naloxone, because it has been suggested that withdrawal symptoms might be reduced by a slower onset of recovery from overdose (Wermeling, 2015). Additional studies are needed to compare the severity and duration of withdrawal precipitated by MCAM and naloxone.

In summary, acute administration of MCAM prevents and reverses the respiratory-depressant effects of heroin and might be superior to naloxone for reversing overdose, because a single injection of MCAM protects against opioid-induced respiratory depression for days. Patients receiving MCAM instead of naloxone could be released from the hospital sooner without concerns about the re-emergence of opioid agonist effects or subsequent overdose if additional opioids are taken. Overall, these studies indicate that MCAM could be useful for treating opioid overdose; however, before this drug is tested in humans, additional preclinical studies are warranted. One factor that needs to be examined in more detail is how the effects of MCAM might change with repeated or extended administration; these effects could be compared with Vivitrol, the slow release formulation of naltrexone. Another factor that might affect the clinical use of MCAM is its onset of action, and additional studies are needed to determine conditions under which it reverses respiratory depression rapidly enough to rescue patients from the potentially lethal effect of opioids. For example, it is possible that MCAM has a faster onset by intramuscular or intranasal administration, the routes by which naloxone is given to human patients, or that particular formulations of MCAM have a more rapid onset of action. Although naloxone had a faster onset of action, MCAM partially reversed heroin-induced respiratory depression within 15 minutes of administration. If reversal of overdose is too slow with all formulations of MCAM alone by all possible routes of administration, it could potentially be combined with naloxone to provide both rapid reversal of and sustained protection from opioid overdose.

\section{Acknowledgments}

We thank Jade Juarez and Anastassia Nelson for their expert technical assistance and Dr. Wouter Koek for comments and suggestions on the manuscript.

\section{Authorship Contributions}

Participated in research design: Gerak, Maguire, Woods, France. Conducted experiments: Gerak.

Contributed new reagents or analytic tools: Husbands, Disney. Performed data analysis: Gerak, Maguire.

Wrote or contributed to the writing of the manuscript: Gerak, Maguire, Woods, Husbands, Disney, France.

\section{References}

Avetian GK, Fiuty P, Mazzella S, Koppa D, Heye V, and Hebbar P (2018) Use of naloxone nasal spray $4 \mathrm{mg}$ in the community setting: a survey of use by community organizations. Curr Med Res Opin 34:573-576.

Briscoe RJ, Winger G, Lewis JW, and Woods JH (2000) Methoclocinnamox: time course of changes in alfentanil-reinforced responding in rhesus monkeys. Psychopharmacology (Berl) 148:393-399.

Broadbear JH, Sumpter TL, Burke TF, Husbands SM, Lewis JW, Woods JH, and Traynor JR (2000) Methocinnamox is a potent, long-lasting, and selective antagonist of morphine-mediated antinociception in the mouse: comparison with clocinnamox, $\beta$-funaltrexamine, and $\beta$-chlornaltrexamine. J Pharmacol Exp Ther 294:933-940.

Butelman ER, Lewis JW, and Woods JH (1996) Methoclocinnamox: agonist and antagonist effects of a novel long-lasting opioid in rhesus monkeys. J Pharmacol Exp Ther 279:934-938.

Dahan A, Aarts L, and Smith TW (2010) Incidence, reversal, and prevention of opioid-induced respiratory depression. Anesthesiology 112:226-238.

France CP, de Costa BR, Jacobson AE, Rice KC, and Woods JH (1990) Apparent affinity of opioid antagonists in morphine-treated rhesus monkeys discriminating between saline and naltrexone. J Pharmacol Exp Ther 252:600-604.

Gatewood AK, Van Wert MJ, Andrada AP, and Surkan PJ (2016) Academic physicians' and medical students' perceived barriers toward bystander administered naloxone as an overdose prevention strategy. Addict Behav 61:40-46. 
Gerak LR, Brandt MR, and France CP (1998) Studies on benzodiazepines and opioids administered alone and in combination in rhesus monkeys: ventilation and drug discrimination. Psychopharmacology (Berl) 137:164-174.

Gerak LR and France CP (2007) Time-dependent decreases in apparent $\mathrm{pA}_{2}$ values for naltrexone studied in combination with morphine in rhesus monkeys. Psychopharmacology (Berl) 193:315-321.

Hall AJ, Logan JE, Toblin RL, Kaplan JA, Kraner JC, Bixler D, Crosby AE, and Paulozzi LJ (2008) Patterns of abuse among unintentional pharmaceutical overdose fatalities. JAMA 300:2613-2620.

Jones CM and McAninch JK (2015) Emergency department visits and overdose deaths from combined use of opioids and benzodiazepines. Am J Prev Med 49: 493-501.

Jones CM, Paulozzi LJ, and Mack KA; Centers for Disease Control and Prevention (CDC) (2014) Alcohol involvement in opioid pain reliever and benzodiazepine drug abuse-related emergency department visits and drug-related deaths - United States, 2010. MMWR Morb Mortal Wkly Rep 63:881-885.

Jones JD, Mogali S, and Comer SD (2012) Polydrug abuse: a review of opioid and benzodiazepine combination use. Drug Alcohol Depend 125:8-18.

Kishioka S, Paronis CA, Lewis JW, and Woods JH (2000a) Buprenorphine and methoclocinnamox: agonist and antagonist effects on respiratory function in rhesus monkeys. Eur J Pharmacol 391:289-297.

Kishioka S, Paronis CA, and Woods JH (2000b) Acute dependence on, but not tolerance to, heroin and morphine as measured by respiratory effects in rhesus monkeys. Eur J Pharmacol 398:121-130.

McDonald R and Strang J (2016) Are take-home naloxone programmes effective? Systematic review utilizing application of the Bradford Hill criteria. Addiction 111: $1177-1187$.

McLaughlin JP, Hill KP, Jiang Q, Sebastian A, Archer S, and Bidlack JM (1999) Nitrocinnamoyl and chlorocinnamoyl derivatives of dihydrocodeinone: in vivo and in vitro characterization of mu-selective agonist and antagonist activity. $J$ Phar macol Exp Ther 289:304-311.

Peckham EM, Barkley LM, Divin MF, Cicero TJ, and Traynor JR (2005) Comparison of the antinociceptive effect of acute morphine in female and male Sprague-Dawley rats using the long-lasting mu-antagonist methocinnamox. Brain Res 1058: 137-147.

Tomassoni AJ, Hawk KF, Jubanyik K, Nogee DP, Durant T, Lynch KL, Patel R, Dinh D, Ulrich A, and D'Onofrio G (2017) Multiple fentanyl overdoses - New Haven, Connecticut, June 23, 2016. MMWR Morb Mortal Wkly Rep 66:107-111.

Vivian JA, Kishioka S, Butelman ER, Broadbear J, Lee KO, and Woods JH (1998) Analgesic, respiratory and heart rate effects of cannabinoid and opioid agonists in rhesus monkeys: antagonist effects of SR 141716A. J Pharmacol Exp Ther 286: 697-703.

Walker EA and Sterious SN (2005) Opioid antagonists differ according to negative intrinsic efficacy in a mouse model of acute dependence. $\mathrm{Br} J$ Pharmacol 145: 975-983.

Walker EA, Zernig G, and Woods JH (1995) Buprenorphine antagonism of mu opioids in the rhesus monkey tail-withdrawal procedure. J Pharmacol Exp Ther 273: 1345-1352.

Weed PF, Gerak LR, and France CP (2018) Ventilatory-depressant effects of opioids alone and in combination with cannabinoids in rhesus monkeys. Eur J Pharmacol 833:94-99.

Wermeling DP (2015) Review of naloxone safety for opioid overdose: practical considerations for new technology and expanded public access. Ther Adv Drug Saf 6: 20-31.

Winger G, Skjoldager P, and Woods JH (1992) Effects of buprenorphine and other opioid agonists and antagonists on alfentanil- and cocaine-reinforced responding in rhesus monkeys. J Pharmacol Exp Ther 261:311-317.

Zernig G, Lewis JW, and Woods JH (1995) Characterization of $\left[{ }^{3} \mathrm{H}\right]$ clocinnamox binding in mouse brain membranes. Analgesia (Elmsford N Y) 1:874-877.

Address correspondence to: Dr. Charles P. France, Department of Pharmacology, University of Texas Health Science Center at San Antonio, 7703 Floyd Curl Drive, Mail Code 7764, San Antonio, TX 78229. E-mail: france@uthscsa.edu 